University of Nebraska - Lincoln

DigitalCommons@University of Nebraska - Lincoln

Faculty Publications from the Department of Electrical \& Computer Engineering, Department Electrical and Computer Engineering

2014

\title{
Enhanced Pool-Boiling Heat Transfer and Critical Heat Flux Using Femtosecond Laser Surface Processing
}

\author{
Corey M. Kruse \\ University of Nebraska-Lincoln \\ Troy P. Anderson \\ University of Nebraska-Lincoln \\ Chris Wilson \\ University of Nebraska-Lincoln \\ Craig A. Zuhlke \\ University of Nebraska-Lincoln, czuhlke@unl.edu \\ Dennis R. Alexander \\ University of Nebraska-Lincoln, dalexander1@unl.edu
}

See next page for additional authors

Follow this and additional works at: https://digitalcommons.unl.edu/electricalengineeringfacpub

Part of the Computer Engineering Commons, and the Electrical and Computer Engineering Commons

Kruse, Corey M.; Anderson, Troy P.; Wilson, Chris; Zuhlke, Craig A.; Alexander, Dennis R.; Gogos, George; and Ndao, Sidy, "Enhanced Pool-Boiling Heat Transfer and Critical Heat Flux Using Femtosecond Laser Surface Processing" (2014). Faculty Publications from the Department of Electrical and Computer Engineering. 289.

https://digitalcommons.unl.edu/electricalengineeringfacpub/289

This Article is brought to you for free and open access by the Electrical \& Computer Engineering, Department of at DigitalCommons@University of Nebraska - Lincoln. It has been accepted for inclusion in Faculty Publications from the Department of Electrical and Computer Engineering by an authorized administrator of DigitalCommons@University of Nebraska - Lincoln. 


\section{Authors}

Corey M. Kruse, Troy P. Anderson, Chris Wilson, Craig A. Zuhlke, Dennis R. Alexander, George Gogos, and Sidy Ndao 


\title{
Enhanced Pool-Boiling Heat Transfer and Critical Heat Flux Using Femtosecond Laser Surface Processing
}

\author{
Corey M. Kruse ${ }^{1}$, Troy Anderson ${ }^{2}$, Chris Wilson ${ }^{2}$, Craig Zuhlke ${ }^{2}$, Dennis Alexander ${ }^{2}$, George Gogos ${ }^{1}$, Sidy Ndao* \\ University of Nebraska - Lincoln, \\ ${ }^{1}$ Mechanical and Materials Engineering \\ ${ }^{2}$ Electrical Engineering \\ Lincoln, Nebraska, U.S., 68588 \\ Email: sndao2@unl.edu
}

\section{ABSTRACT}

In this paper, we present the experimental investigation of pool boiling heat transfer on multiscale (micro/nano) functionalized metallic surfaces. The multiscale structures were fabricated via a femtosecond laser surface process (FLSP) technique which forms mound-like microstructures covered by layers of nanoparticles. Using a pool boiling experimental setup with deionized water as the working fluid, both the heat transfer coefficient and critical heat flux were investigated. The polished reference sample was found to have a critical heat flux of $91 \mathrm{~W} / \mathrm{cm}^{2}$ at $40{ }^{\circ} \mathrm{C}$ of superheat and a maximum heat transfer coefficient of $23,000 \mathrm{~W} / \mathrm{m}^{2}-\mathrm{K}$. The processed sample was found to have a critical heat flux of 122 $\mathrm{W} / \mathrm{cm}^{2}$ at $18{ }^{\circ} \mathrm{C}$ superheat and a maximum heat transfer coefficient of $67,400 \mathrm{~W} / \mathrm{m}^{2}-\mathrm{K}$. Flow visualization revealed nucleate boiling to be the main two-phase heat transfer mechanism. The overall heat transfer performance of the metallic multiscale structured surface has been attributed to both augmented heat transfer surface area and enhanced nucleate boiling regime. On the other hand, increase in the critical heat flux can be attributed to the superhydrophilic nature of the laser processed surface and the presence of nanoparticle layers.

KEY WORDS: Pool Boiling, Critical Heat Flux, Femtosecond Laser Surface Processing, heat transfer coefficient, Metallic Surface Enhancement

\section{INTRODUCTION}

Two-phase heat transfer on micro and nanostructured surfaces has attracted much research interest in recent time. This is due to the observed high heat transfer coefficients and critical heat flux. Most pool boiling experiments for enhanced heat transfer have been conducted on micro and nanostructured surfaces fabricated using complex fabrication techniques such as etching and film depositions carried out in highly controlled environments (i.e., cleanroom). These techniques have been very effective at increasing the critical heat flux (CHF) as well as the heat transfer coefficient (HTC) through a combination of increased surface roughness, wettability, and porosity. These microfabrication techniques have been used to create very organized arrays of microstructures ranging from pillars to microchannels and have demonstrated CHF values of $150-200 \mathrm{~W} / \mathrm{cm}^{2}$ [1], [2] for pillars and $100 \mathrm{~W} / \mathrm{cm}^{2}$ [3] for microchannels. When nanoscale features are added to these microstructures, the critical heat flux can be further increased to $230 \mathrm{~W} / \mathrm{cm}^{2}$ for the pillar structures [1] and $160 \mathrm{~W} / \mathrm{cm}^{2}$ for the microchannels with nanostructures [3]. This shows that hierarchical structures can significantly increase the performance of heat transfer surfaces. In addition to surface microstructuring, it has also been shown that surface chemical properties such as a combination or network of hydrophilic and hydrophobic areas on a surface can significantly enhance the heat transfer performance as well. The hydrophobic areas lead to easily activated nucleation sites while the hydrophilic areas prevent the vapor from forming a stable layer and thus delaying the critical heat flux [4], [5].

In addition to microstructures, silicon and copper nanowire coatings have also been used for two-phase heat transfer enhancement. These types of surfaces have been shown to produce CHF values in the range of $120-200 \mathrm{~W} / \mathrm{cm}^{2}$ [6]-[8]. Such CHF enhancements have been attributed to high nucleation density, superhydrophilicity, and enhanced capillary pumping. All of the previously mentioned experimental results were conducted with a heat transfer surface comprised of a silicon base material which is advantageous in small applications such as electronics cooling. These types of surface enhancement techniques are however not practical for applications which require metallic heat transfer surfaces and much larger areas.

Some work has been done to enhance heat transfer surfaces with a metallic base. These enhancement methods involve oxidation processes or material deposition to achieve the desired micro/nanostructures and are often limited to a certain type base material. Through the use of an anodic oxidation process on a zirconium alloy surface, CHF values as high as $200 \mathrm{~W} / \mathrm{cm}^{2}$ have been achieved [9]. In other work, alumina was deposited onto platinum using atomic layer deposition [10] and zinc oxide was deposited onto copper and aluminum surfaces in order to enhance two-phase heat transfer [11]. The alumina deposition on platinum resulted in a CHF of around $120 \mathrm{~W} / \mathrm{cm}^{2}$ while the zinc oxide covered surfaced only reached maximum heat fluxes of about $65 \mathrm{~W} / \mathrm{cm}^{2}$.

Our current research focuses on using a technique referred to as Femtosecond Laser Surface Processing (FLSP). This technique uses an ultra-fast laser to ablate and form a selforganized array of mound like microstructures with a nanoparticle layer on any metallic surface. This method is a one step process that has the advantage of being able to process nearly any size of area with a very high precision. This technique was used to enhance the heat transfer properties of a stainless steel surface used for pool boiling two phase heat transfer. 


\section{EXPERIMENTAL PROCEDURES}

\section{Laser Manufacturing}

Multiscale surfaces (surfaces with roughness on both the micrometer and nanometer scales) are commonly applied for the fabrication of advanced wettability surfaces that range from superhydrophobic to superhydrophilic [12]-[17]. Indeed, such surfaces are considered to be biologically inspired as they often mimic the surfaces of plant leaves; one iconic example is the superhydrophobic lotus leaf, which exhibits self-cleaning properties due in part to multiscale surface features [18], [19] . For such structured surfaces, the relative sizes of both micrometer and nanometer scale structures are critical for the control of not only the contact angle, but also the adhesion and wetting state (e.g. the fully-wetting Wenzel state or the hybrid Cassie-Baxter state) [19].

Femtosecond laser surface processing (FLSP) is rapidly emerging as a powerful and dynamic method for the fabrication of biologically inspired multiscale surface structures. Using this process, surfaces generally consist of self-organized, quasi-periodic micron-scale conical or mound structures that are covered in a layer of nanoparticles [20][27]. These surface structures are formed through a complex combination of multiple growth mechanisms including laser ablation, capillary flow of laser-induced melt layers, and redeposition of ablated material.

A schematic of the FLSP setup is shown in Figure 1. The laser was a Ti:Sapphire (Spitfire, Spectra Physics) that produced $\sim 50$ femtosecond pulses centered around $800 \mathrm{~nm}$ at a $1 \mathrm{kHz}$ repetition rate. The laser power was controlled through a combination of a half waveplate and a polarizer. A refractive Gauss-to-top hat beam shaper (Eksma Optics, GTH4-2.2FA) was used to generate a top hat beam with a square profile; this ensured that the laser fluence on the sample was uniform. The sample was placed on a computer-controlled 3D translation stage and translated through the beam path of the laser in order to process an area larger than the laser spot size. The number of pulses incident on the sample was controlled by the translation speed of the sample.

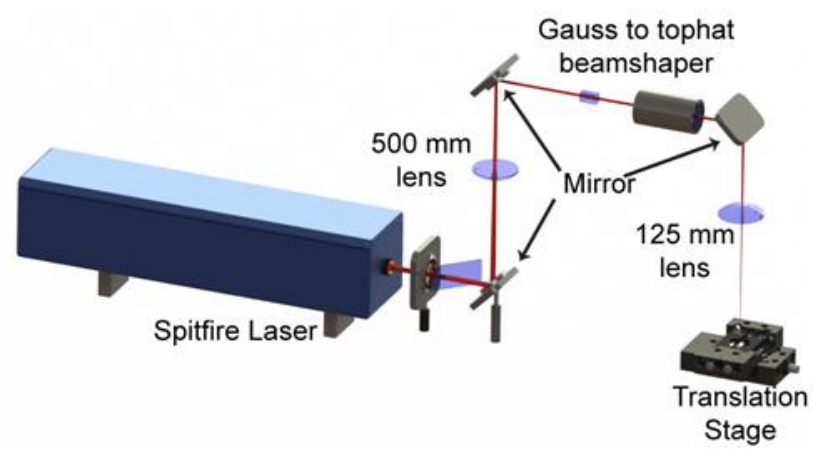

Fig.1 Schematic of the femtosecond laser surface processing (FLSP)

\section{Tailoring Multiscale Surfaces}

The size and shape of self-organized surface structures fabricated via FLSP are controlled through various fabrication parameters including the laser fluence, the number of laser shots per area incident on the sample, and the composition and pressure of the atmosphere during processing. The fluence and shot number are used as control parameters for determining the type of microstructure created on the surface. These parameters are two contrasting ways of controlling the total dose of the laser energy transferred to the substrate. To illustrate this, consider that a given amount of laser energy can be transferred to a target substrate either through a small number of laser pulses with a large fluence or through a large number of laser pulses with a small fluence. However, the laser fluence critically impacts the laser-matter interaction mechanisms attributed to the development of multiscale structures; we recently published a shot-by-shot study of the ability of the laser fluence to influence the physical formation mechanisms of the self-organized surface structures and utilized this control to fabricate multiscale metallic surface structures that rise above the original surface [27]. Thus, control of the laser dose via a calculated selection of both the laser fluence and the number of pulses on the sample is a convenient method to produce a range of unique surface morphologies.

The type of surface morphology that is created depends on the balance of the three main mechanisms that govern how the self-organized microstructures are formed. The three main mechanisms are preferential ablation, fluid flow, and material redeposition. These are depicted in Figure 2. The combination of these three mechanisms defines the properties and geometry of the self-organized microstructures. These mechanisms are controlled by changing the fluence and shot combination. A detailed description of the development and formation of these structures is beyond the scope of this paper; a more detailed description is provided by Zuhlke, et al [27].

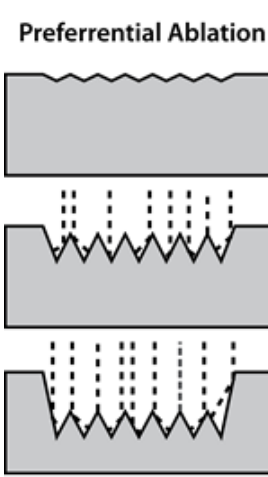

(a)
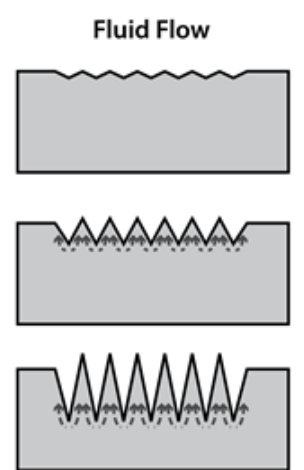

(b)
Redeposition
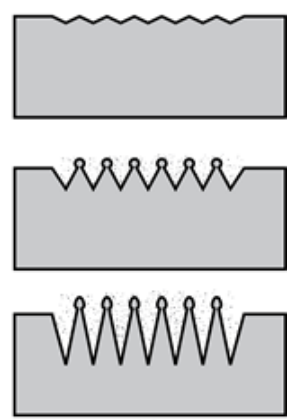

(c)
Fig.2 Schematic illustrations of three growth mechanisms leading to the development of multiscale surface features from surface precursor sites upon laser irradiation. (a) Material is ablated away around a scattering site to form structures. (b) Material is melted and flows to form structures. (c) Particles are redeposited to form structures. 


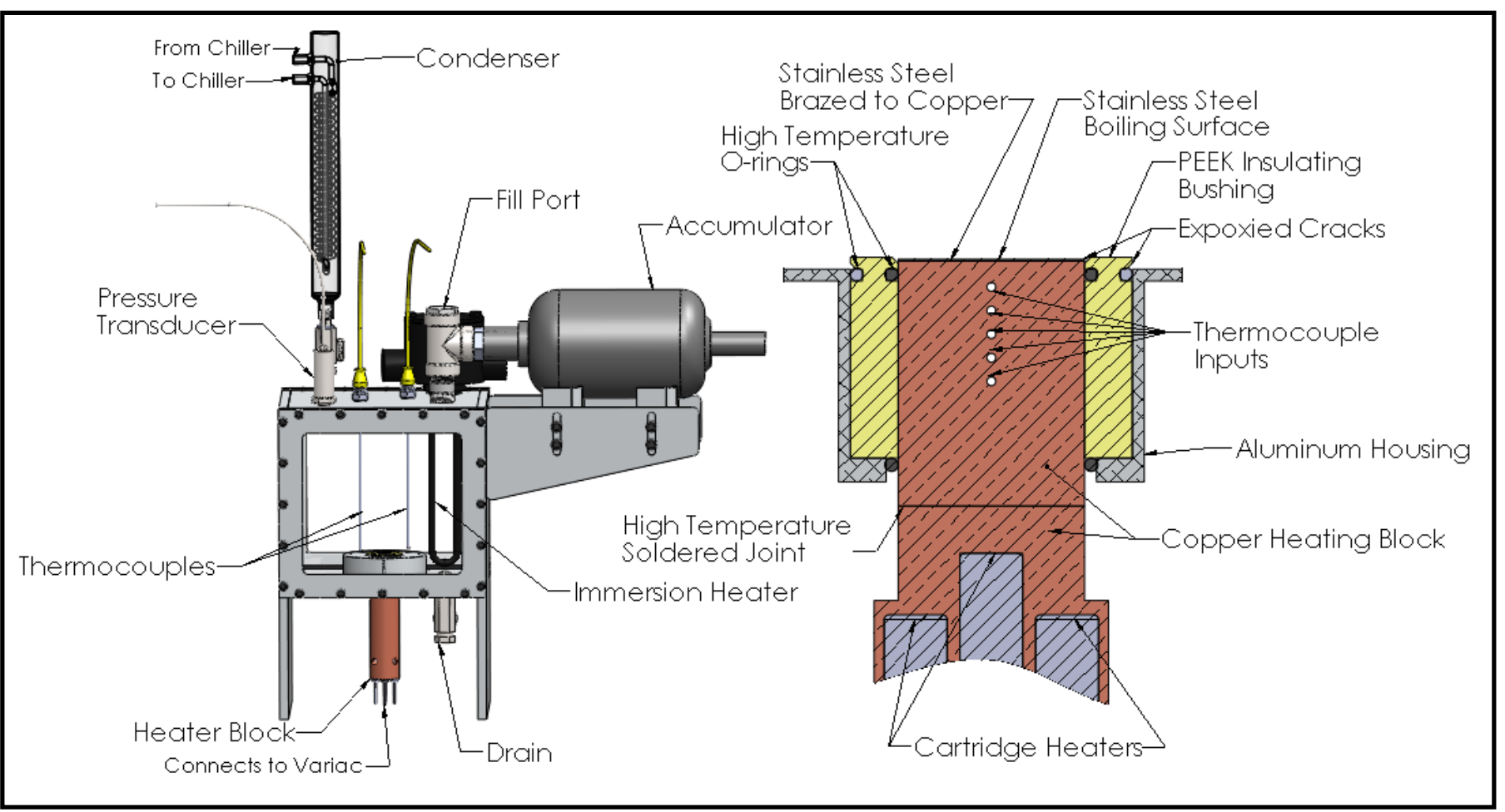

Fig. 3 Left - Full experimental pool boiling setup, Right - Cross sectional view of heating block and boiling surface

\section{Pool Boiling Experimental Setup and Procedure}

A closed system pool boiling experimental setup was used for the experimental investigations. This setup is highlighted in Figure 3. The test rig was designed to accommodate a variety of working fluids. For the presented results, deionized water was used as the working fluid. The test rig was filled with eight liters of deionized water for the present experiments. The system was brought to the saturation temperature of the water by the use of an immersion heater (Omega - MT-112E2/120V) controlled by an analog variac. The water temperature and internal pressure were monitored with the use of two K-type thermocouples (Omega - M12KIN18-U-6-D) and a pressure transducer (Omega MMA100V5P4C0T4A5CE) connected to a National Instrument Data Acquisition Board. The water was degassed for a half hour before measurements were taken. The steam produced was directed through a coil condenser (Quark Glass - qc-6-4sp) and vented to the atmosphere. The condenser was supplied with cold water with the use of a chiller. The test rig also includes a bladder accumulator for regulating the overall system pressure. This feature of the boiling rig was not used for the present experiment as all measurements were taken at atmospheric pressure. Two Lexan view windows were incorporated into the test rig to allow for flow visualization.

Once the system was allowed to reach the saturation temperature of the water, power to the heater was gradually increased using a copper heating block containing five cartridge heaters (Omega - CSH-203450/120V) controlled with an analog variac. This copper heating block was attached to the upper copper heating block (see Fig. 3) with the use of a high temperature solder (McMaster - 7685A12). The upper copper heating block has five thermocouple holes drilled to the center of the block. The thermocouples (located $3.175 \mathrm{~mm}$ apart) were used to measure the temperature gradient within the block and to calculate the heat flux. Heat flux values were recorded after the system had reached steady state confirmed via an in-house LabVIEW program. The test section consists of a $25.4 \mathrm{~mm}$ diameter and $.254 \mathrm{~mm}$ thick 304 stainless steel disk. The section was brazed onto the copper heating block using a silver solder paste (Muggyweld - SSQ-6) to ensure an efficient contact between the two. The surface temperature on the exposed surface of the test section was interpolated with the use of measured temperature gradient along the heating block. The contact resistance between the copper and stainless steel was neglected due to the very thin and the highly conductive silver solder braze used. A high temperature PEEK plastic insulating bushing was used to insulate the upper copper heating block. Fiberglass insulation was used to insulate the lower copper heating block (not pictures in Fig. 3). High temperature silicon o-rings were also used to seal between the concentric heating and insulating pieces. To ensure that nucleation would not initially occur on the outer edges of the boiling surface, a special epoxy (Mcmaster 7513A1) was used for bonding dissimilar materials.

\section{Heat Flux and Uncertainty Calculation}

The heat flux was calculated through the use of the measured temperature gradient. The five equally spaced thermocouples located in the upper heating block were used to measure the temperature distribution along the axis of the 
heating block and calculate the heat flux. The heat flux was calculated as:

$$
q^{\prime \prime}=k_{c} \frac{T_{1}-T_{2}}{x}(1)
$$

where $k_{c}$ is the thermal conductivity of the copper, $T_{1}$ and $T_{2}$ are the thermocouple temperatures and $x$ is the thermocouple separation. The thermal conductivity of copper was taken to be constant at a value of $401 \mathrm{~W} / \mathrm{mK}$. The temperature gradient and heat flux were measured at the four locations between the five thermocouples and then averaged to give the reported value. The critical heat flux is determined when the monitored thermocouple temperatures spike on the order of $100{ }^{\circ} \mathrm{C}$ and burnout occurs. Experimental values beyond this point could not be obtained due to the limitations of the experimental rig.

In this experiment the power input to the heating source was not used to calculate the heat flux. The radial heat loss was minimized by insulating the copper heating blocks. The upper heating block was insulated with a PEEK plastic bushing $\left(\mathrm{k}_{\mathrm{p}}=.25 \mathrm{~W} / \mathrm{mK}\right)$. The thickness of this insulating bushing is $.635 \mathrm{~cm}$ thick. At heat fluxes near the critical heat flux, the thermocouple nearest to the surface recorded a value of approximately $147{ }^{\circ} \mathrm{C}$ for the processed sample. The radial heat flux can be estimated across insulating PEEK bushing if the aluminum housing (see Fig. 3) is assumed to be at $100{ }^{\circ} \mathrm{C}$ due to it being in contact with the saturated water. It is also assumed that the temperature at the copper/PEEK interface is $147^{\circ} \mathrm{C}$ due to the highly conductive nature of the copper. The radial heat flux is estimated with Equation 2.

$$
q^{\prime \prime}{ }_{r}=k_{p} \frac{\left(T_{i}-T_{w}\right)}{r_{p}}(2)
$$

Where $k_{p}$ is the PEEK thermal conductivity, $r_{p}$ is the PEEK radius, $T_{w}$ is the aluminum temperature at the wall, and $T_{i}$ is the interface temperature. It is found that this heat flux is approximately $.2 \mathrm{~W} / \mathrm{cm}^{2}$. This radial heat loss is less than $1 \%$ of the total heat flux measured at the critical heat flux.

The uncertainty of the heat flux value as well as the surface temperature was calculated using the standard error propagation equation. The standard deviation of the heat flux based on the accuracies of the measurement equipment is given as follows.

$$
\Delta q^{\prime \prime}=\sqrt{\left(\frac{\partial q^{\prime \prime}}{\partial x} \Delta x\right)^{2}+\left(\frac{\partial q^{\prime \prime}}{\partial T_{1}} \Delta T\right)^{2}+\left(\frac{\partial q^{\prime \prime}}{\partial T_{2}} \Delta T\right)^{2}}
$$

The variation of the thermocouple separation $(\Delta x)$ is $.076 \mathrm{~mm}$ and the thermocouple variation $(\Delta T)$ is $1{ }^{\circ} \mathrm{C}$. This leads to an estimated error of approximately $15 \%$.

The surface temperature was interpolated from the calculated heat flux. This interpolation considered both the copper material as well as the stainless steel wafer. The contact between the two materials was assumed to be ideal due to the highly conductive and very thin layer of silver braze used to join the two. The surface temperature equation is as follows:

$$
T_{s}=T_{1}-\frac{q^{\prime \prime} x_{1}}{k_{c}}-\frac{q^{\prime \prime} x_{S S}}{k_{S S}}(4)
$$

Where $T_{1}$ is the thermocouple temperature located closest to the surface, $x_{1}$ is the distance between $T_{1}$ and the stainless steel wafer, $x_{s s}$ is the stainless steel wafer thickness, and $k_{c}$ and $k_{s s}$ are the copper and stainless steel thermal conductivities. The stainless steel thermal conductivity was linearly extrapolated with temperature. The estimated error for the surface temperature was determined with a similar equation to equation 3.

$$
\Delta T_{s}=\sqrt{\left(\frac{\partial T_{s}}{\partial T_{1}} \Delta T\right)^{2}+\left(\frac{\partial T_{s}}{\partial q^{\prime \prime}} \Delta q^{\prime \prime}\right)^{2}+\left(\frac{\partial T_{s}}{\partial x_{1}} \Delta x_{1}\right)^{2}+\left(\frac{\partial T_{s}}{\partial x_{s s}} \Delta x_{s s}\right)^{2}}
$$

The variation $x_{1}\left(\Delta x_{1}\right)$ is $0.07 \mathrm{~mm}$ and the variation of the wafer thickness $\left(\Delta x_{s s}\right)$ is $0.003 \mathrm{~mm}$. With these variations the error in the surface temperature calculation is approximately $4 \%$.

\section{Surface Characterization}

In the current experiment, a polished stainless steel surface and a laser processed surface were tested and compared for their boiling heat transfer performance. The polished stainless steel sample was polished to a mirror finish through the use of a series of buffing compounds. The laser processed surface was fabricated to have a self-organized mound like microstructure with a layer of nanoparticles covering the mound structures.

Several techniques were used to characterize each surface. A Rame-Hart Model 590 F4 Series Goniometer and Tensiometer was used to measure the contact angle of both the polished and processed sample. Deionized water was used for this measurement. The contact angle of the polished surface was found to be approximately $80^{\circ}$. FLSP results in a porous surface layer due to the dense layer of nanoparticles that cover the microstructures [28]. The porous layer results in a surface with high wicking capabilities and a contact angle of nearly zero.

In order to characterize the processed surface, two methods were used: Scanning Electron Microscopy (SEM imaging) and Laser-confocal surface profilometry. The results from these two methods are shown in Figure 4. The SEM images show the self-organized nature of the mound like microstructures. The mound structures are covered in a layer of nanoparticles that can be seen in part B of Figure 4 from the formed lines and ridges across each microstructure. It is important to note that the nanoparticles produce porous layers above the microstructures. In our previous work, TEM imaging was used to characterize the nature of the nanoparticle layer [28]. It was found then that the nanoparticle layer was responsible for a significant portion (nearly one-third) of the total microstructure height, one-third of it.

Laser-confocal microscopy was used to create a 3D profile of the processed surface from which physical dimensions of the microstructures could be measured. The 3D surface generated from the laser-confocal microscope can be seen in part $\mathrm{C}$ of Figure 4. The average peak to valley height of the microstructures was found to be around $31 \mu \mathrm{m}$ tall. The surface area ratio, which is defined as the ratio of total surface area divided by the cross sectional planar surface area, was found to be 4.7. The rms surface roughness was also determined to be $6.4 \mu \mathrm{m}$. 


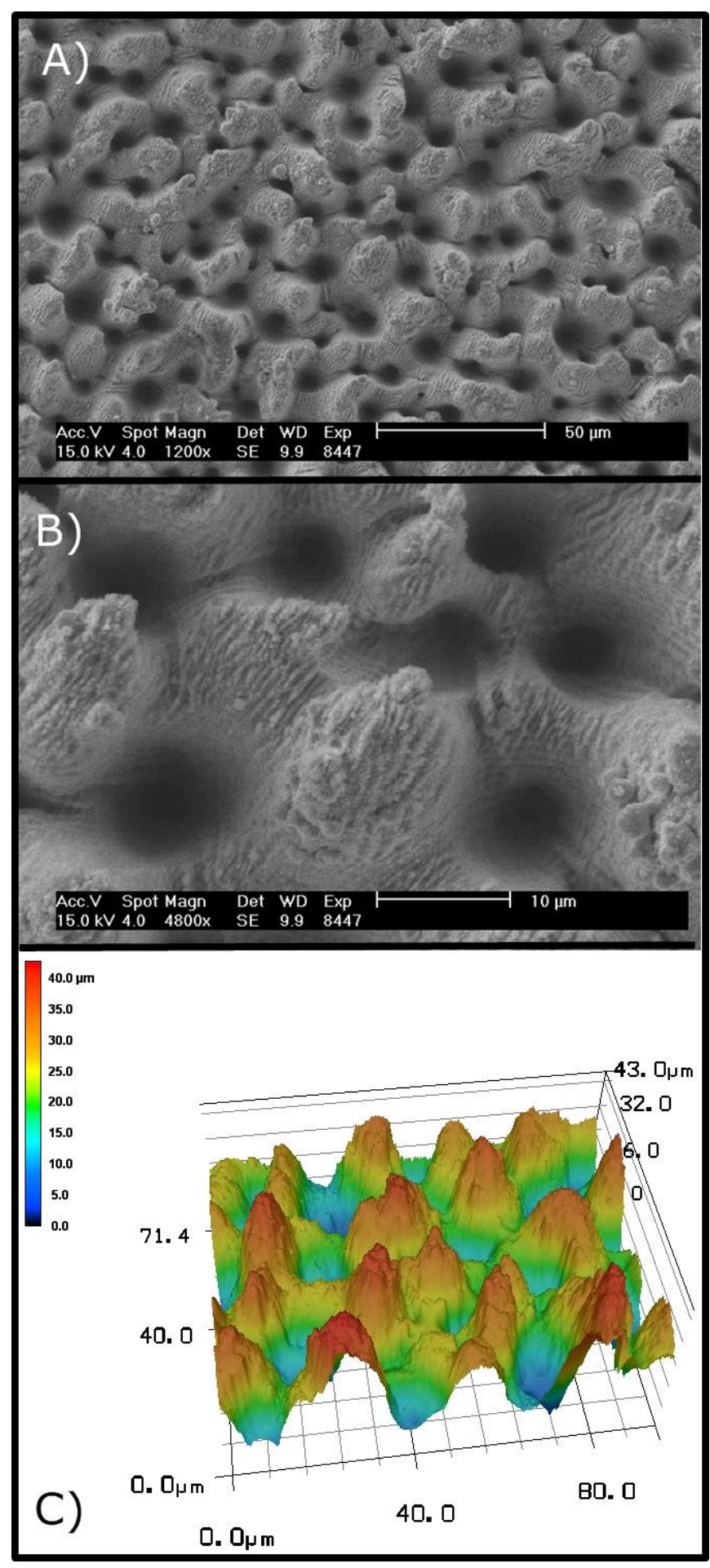

Fig. 4 SEM and laser confocal microscope images of the femtosecond laser processed surface. A) SEM magnification of 1200x and scale bar of $50 \mu \mathrm{m}, \mathrm{B}$ ) SEM image magnification of 4800x and scale bar of 10 $\mu \mathrm{m}, \mathrm{C})$ Laser confocal 3D generated image.

\section{RESULTS}

For each of the two sample surfaces tested, measurements were first taken at low heat fluxes and then the heat flux was gradually increased until the critical heat flux was attained. The results are shown in Figure 5. It can be seen from this figure that there was a drastic difference between the two surfaces in their heat transfer performance. The processed surface consistently outperformed the polished sample at every surface temperature. The polished sample was found to have a critical heat flux of $91 \mathrm{~W} / \mathrm{cm}^{2}$ at a surface superheat of $40^{\circ} \mathrm{C}$. At this temperature and heat flux, the heat transfer coefficient was calculated to be $22,800 \mathrm{~W} / \mathrm{m}^{2} \mathrm{~K}$. On the other hand, the processed surface was found to have a critical heat flux of $122 \mathrm{~W} / \mathrm{cm}^{2}$ at a surface superheat of $18{ }^{\circ} \mathrm{C}$. This heat flux and surface temperature combination resulted in a heat transfer coefficient of $67,400 \mathrm{~W} / \mathrm{m}^{2} \mathrm{~K}$. The processed surface resulted in a maximum HTC approximately 7.5 times higher than the HTC of the polished surface for the same surface temperature. The shift of the boiling curve to the left with the processed surface is very advantageous for most heat transfer applications as it allows for a large amount of heat to be transferred at relatively low surface temperatures. The steep slope of the curve is also advantageous because of the relatively small surface temperature change (around $10{ }^{\circ} \mathrm{C}$ ). This small temperature change at varying heat fluxes is especially beneficial for applications that see rapidly changing heat transfer demands. It is believed that the reason the surface superheat corresponding to the processed sample reaches a maximum is due to the fact that the boiling mechanism is approaching the transition state to film boiling and is becoming very unstable. It is also possible that additional nucleation sites become active at this high heat flux, but it is not possible to view this due to the nature of the large vapor bubbles leaving the surface.

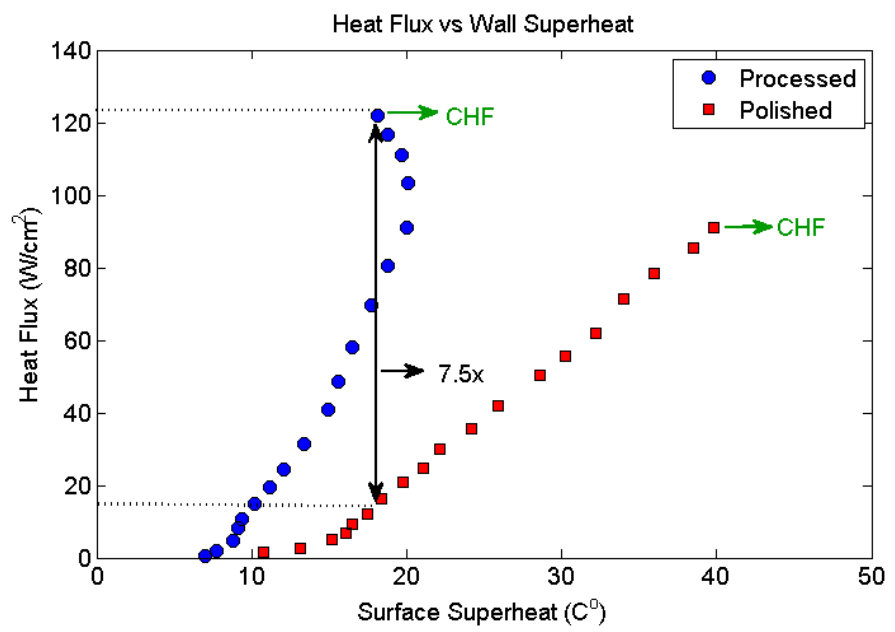

Fig. 5 Heat fluxes with respect to surface superheat for both the laser processed and polished stainless steel surfaces.

As expected from the data shown in Figure 5, the two surfaces displayed visually very different boiling characteristics as can be seen in Figure 6. Bubble nucleation was first observed at about $10{ }^{\circ} \mathrm{C}$ of wall superheat for the polished sample. In most cases, nucleation started in the center of the surface however in few cases, it initiated at the edges of the sample though epoxy was applied at the edges of the sample in order to limit this unwanted nucleation. At low heat fluxes, only a few nucleation sites were active for the polished surface. These active sites produced large bubbles which were 
slow to detach from the surface as seen in Figure 6 (Top image)

As for the processed sample, the nucleation process appeared very different. First, the onset of nucleation occurred at a much lower temperature than the polished sample. This occurred at a superheat temperature of $7{ }^{\circ} \mathrm{C}$. At this temperature, there was also nearly zero nucleation at the edges of the sample unlike with the polished surface. Also, at the onset of nucleation, there were significantly more active nucleation sites. These active sites produced very small bubbles which quickly formed and detached from the surface - higher nucleation site density and bubble departure rates. In Figure 6 (bottom image), the early stages of nucleation are shown for the laser processed surface.

As can be seen from both Figure 5 and 6, the femtosecond laser surface processing technique has a significant effect on the boiling performance of a stainless steel heat transfer surface. This process creates a unique hierarchical structure consisting of mounds covered in a dense porous layer of nanoparticles. This combination results in a surface with a very low contact angle and high wicking capabilities. This combination prevents the onset of film boiling by maintaining the liquid/solid contact at high heat fluxes. This results in the achievement of a higher critical heat flux. The femtosecond laser surface process also creates a very rough surface. The microstructures produce an increased surface area ratio while the nanoparticle coating creates an abundance of potential nucleation sites. This combination results in more heat transfer surface area exposed to the liquid as well a more efficient nucleation process further explaining the superiority of the laser processed surface over the polished one.

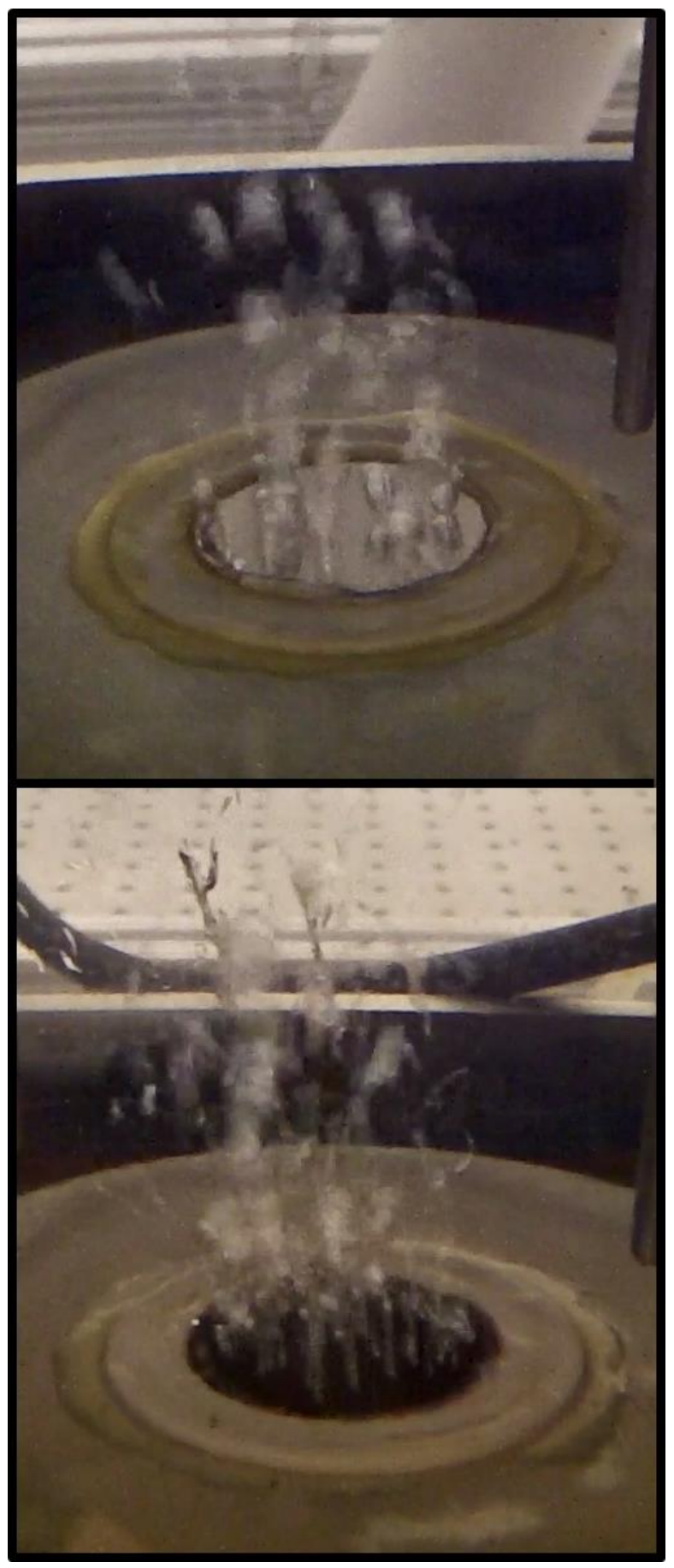

Fig. 6 Onset of boiling nucleation for both heat transfer surfaces: Top - polished sample, $13{ }^{\circ} \mathrm{C}$ superheat and 3 $\mathrm{W} / \mathrm{cm}^{2}$, Bottom - processed sample, $7.7{ }^{\circ} \mathrm{C}$ and 2 $\mathrm{W} / \mathrm{cm}^{2}$

\section{CONCLUSION}

Through the use of a femtosecond laser surface process (FLSP), a stainless steel surface was fabricated with hierarchical micro/nanostructures. The structures consist of mound like microstructures covered by a dense layer of nanoparticles resulting in a superwicking surface with augmented surface area and increased nucleation sites probability. From the experimental results, it was shown that 
the processed surface was able to increase the critical heat flux of the stainless steel sample from 91 to $122 \mathrm{~W} / \mathrm{cm}^{2}$ while also increasing the heat transfer coefficient by nearly 7.5 times to a value of $67,400 \mathrm{~W} / \mathrm{m}^{2} \mathrm{~K}$ when compared to a smooth surface. Heat transfer enhancement has been attributed to augmented surface area, enhanced nucleate boiling, and surface capillary wicking action. This method of surface enhancement is unique in that it creates the micro/nanostructure with the base material and thus is capable of producing a robust and permanent surface modification on nearly any metallic surface.

\section{ACKNOWLEDGMENT}

This work has been supported by a grant through the Nebraska Center for Energy Sciences Research (NCESR) with funds provided by Nebraska Public Power District (NPPD) to the University of Nebraska - Lincoln (UNL) No. 4200000844, by funds from the Air Force Research Laboratory (AFRL) High Energy Laser-Joint Technology Office (HEL-JTO) No. FA9451-12-D-019/0001, JTO Number: 12-BAA-0467, and by funds from the Department of Mechanical and Materials Engineering and the College of Engineering at UNL, awarded to $\mathrm{SN}$.

\section{REFERENCES}

[1] S. Kim, H. D. Kim, H. Kim, H. S. Ahn, H. Jo, J. Kim, and M. H. Kim, "Effects of Nano-Fluid and Surfaces with Nano Structure on the Increase of CHF," Exp. Therm. Fluid Sci., vol. 34, no. 4, pp. 487-495, May 2010.

[2] K.-H. Chu, R. Enright, and E. N. Wang, "Structured Surfaces for Enhanced Pool Boiling Heat Transfer," Appl. Phys. Lett., vol. 100, no. 24, p. 241603, 2012.

[3] Z. Yao, Y.-W. Lu, and S. G. Kandlikar, "Micro/nano Hierarchical Structure in Microchannel Heat Sink for Boiling Enhancement," in 2012 IEEE 25th International Conference on Micro Electro Mechanical Systems (MEMS), 2012, pp. 285-288.

[4] A. R. Betz, J. Jenkins, C.-J. “Cj” Kim, and D. Attinger, "Boiling Heat Transfer on Superhydrophilic, Superhydrophobic, and Superbiphilic Surfaces," Int. J. Heat Mass Transf., vol. 57, no. 2, pp. 733-741, Feb. 2013.

[5] A. R. Betz, J. Xu, H. Qiu, and D. Attinger, "Do Surfaces with Mixed Hydrophilic and Hydrophobic Areas Enhance Pool Boiling?," Appl. Phys. Lett., vol. 97, no. 14, p. 141909, 2010.

[6] Z. Yao, Y.-W. Lu, and S. G. Kandlikar, "Effects of Nanowire Height on Pool Boiling Performance of Water on Silicon Chips," Int. J. Therm. Sci., vol. 50, no. 11, pp. 2084-2090, Nov. 2011.

[7] M.-C. Lu, R. Chen, V. Srinivasan, V. P. Carey, and A. Majumdar, "Critical Heat Flux of Pool Boiling on Si Nanowire Array-Coated Surfaces," Int. J. Heat Mass Transf., vol. 54, no. 25-26, pp. 5359-5367, Dec. 2011.

[8] R. Chen, M.-C. Lu, V. Srinivasan, Z. Wang, H. H. Cho, and A. Majumdar, "Nanowires for Enhanced
Boiling Heat Transfer.," Nano Lett., vol. 9, no. 2, pp. 548-53, Feb. 2009.

[9] H. S. Ahn, C. Lee, J. Kim, and M. H. Kim, "The Effect of Capillary Wicking Action of Micro/nano Structures on Pool Boiling Critical Heat Flux," Int. J. Heat Mass Transf., vol. 55, no. 1-3, pp. 89-92, Jan. 2012.

[10] B. Feng, K. Weaver, and G. P. Peterson, "Enhancement of Critical Heat Flux in Pool Boiling Using Atomic Layer Deposition of Alumina," Appl. Phys. Lett., vol. 100, no. 5, p. 053120, 2012.

[11] T. J. Hendricks, S. Krishnan, C. Choi, C.-H. Chang, and B. Paul, "Enhancement of Pool-Boiling Heat Transfer Using Nanostructured Surfaces on Aluminum and Copper," Int. J. Heat Mass Transf., vol. 53, no. 15-16, pp. 3357-3365, Jul. 2010.

[12] P. Bizi-Bandoki, S. Benayoun, S. Valette, B. Beaugiraud, and E. Audouard, "Modifications of Roughness and Wettability Properties of Metals Induced by Femtosecond Laser Treatment," Appl. Surf. Sci., vol. 257, no. 12, pp. 5213-5218, Apr. 2011. [13] Z. K. Wang, H. Y. Zheng, and H. M. Xia,

"Femtosecond Laser-Induced Modification of Surface Wettability of PMMA for Fluid Separation in Microchannels," Microfluid. Nanofluidics, vol. 10, no. 1, pp. 225-229, Jul. 2010.

[14] J. Wu, J. Xia, W. Lei, and B. Wang, "A One-Step Method to Fabricate Lotus Leaves-Like ZnO Film," Mater. Lett., vol. 65, no. 3, pp. 477-479, Feb. 2011.

[15] T. Baldacchini, J. E. Carey, M. Zhou, and E. Mazur, "Superhydrophobic Surfaces Prepared by Microstructuring of Silicon Using a Femtosecond Laser.," Langmuir, vol. 22, no. 11, pp. 4917-9, May 2006.

[16] C. H. Crouch, J. E. Carey, J. M. Warrender, M. J. Aziz, E. Mazur, and F. . G nin, "Comparison of Structure and Properties of Femtosecond and Nanosecond Laser-Structured Silicon," Appl. Phys. Lett., vol. 84, no. 11, p. 1850, 2004.

[17] S. I. Dolgaev, S. V. Lavrishev, a. a. Lyalin, a. V. Simakin, V. V. Voronov, and G. a. Shafeev, "Formation of Conical Microstructures Upon Laser Evaporation of Solids,” Appl. Phys. A Mater. Sci. Process., vol. 73, no. 2, pp. 177-181, Aug. 2001.

[18] K. Koch, B. Bhushan, Y. C. Jung, and W. Barthlott, "Fabrication of Artificial Lotus Leaves and Significance of Hierarchical Structure for Superhydrophobicity and Low Adhesion," Soft Matter, vol. 5, no. 7, p. 1386, 2009.

[19] E. Stratakis, a Ranella, and C. Fotakis, "Biomimetic Micro/nanostructured Functional Surfaces for Microfluidic and Tissue Engineering Applications.," Biomicrofluidics, vol. 5, no. 1, p. 13411, Jan. 2011.
B. Tull, J. Carey, and E. Mazur, "Silicon Surface Morphologies after Femtosecond Laser Irradiation," Mrs ..., vol. 31, no. August, pp. 626-633, 2006.

B. Wu, M. Zhou, J. Li, X. Ye, G. Li, and L. Cai, "Superhydrophobic Surfaces Fabricated by Microstructuring of Stainless Steel Using a 
Femtosecond Laser,” Appl. Surf. Sci., vol. 256, no. 1, pp. 6166, Oct. 2009.

[22] B. K. Nayak, M. C. Gupta, and K. W. Kolasinski, "Spontaneous Formation of Nanospiked

Microstructures in Germanium by Femtosecond Laser Irradiation," Nanotechnology, vol. 18, no. 19, p. 195302, May 2007.

[23] B. K. Nayak and M. C. Gupta, "Ultrafast LaserInduced Self-Organized Conical Micro/nano Surface Structures and Their Origin," Opt. Lasers Eng., vol. 48, no. 10, pp. 966-973, Oct. 2010.

[24] T.-H. Her, R. J. Finlay, C. Wu, and E. Mazur, "Femtosecond Laser-Induced Formation of Spikes on Silicon,” Appl. Phys. A Mater. Sci. Process., vol. 70, no. 4, pp. 383-385, Apr. 2000.

[25] T. ong Hwang and C. Guo, "Polarization and Angular Effects of Femtosecond Laser-Induced
Conical Microstructures on Ni," J. Appl. Phys., vol. 111, no. 8, p. 083518, 2012.

[26] A. . Vorobyev and C. Guo, "Direct Femtosecond Laser Surface Nano/microstructuring and Its Applications," Laser Photon. Rev., vol. 7, no. 3, pp. 385-407, May 2013.

[27] C. Zuhlke, T. Anderson, and D. Alexander, "Formation of Multiscale Surface Structures on Nickel via Above Surface Growth and Below Surface Growth Mechanisms Using Femtosecond Laser Pulses," Opt. Express, vol. 21, no. 7, pp. 97-98, 2013.

[28] C. Kruse, T. Anderson, C. Wilson, C. Zuhlke, D. Alexander, G. Gogos, and S. Ndao, "Extraordinary Shifts of the Leidenfrost Temperature from Multiscale Micro/nanostructured Surfaces.," Langmuir, vol. 29, no. 31, pp. 9798-806, Aug. 2013. 